\title{
ДИПЛОМАТИЯ
}

Сыченко Е.В.

\section{ЗАМЕЧАНИЯ КОМИТЕТА ООН ПО ПРАВАМ ЧЕЛОВЕКА К РОССИИ, ПРИНЯТЫЕ 31 МАРТА 2015 ГОДА: ИХ ПРАВОВОЙ СТАТУС И ПРОБЛЕМА ЗАЩИТЫ ПРАВ ЧЕЛОВЕКА НА ТЕРРИТОРИИ ВОСТОЧНОЙ УКРАИНЫ}

\begin{abstract}
Аннотация. В настоящей статье рассмотрены соображения Комитета ООН по правам человека в результате рассмотрения доклада Российской Федерации о выполнении Международного пакта о гражданских и политических правах. Комитет отметил позитивные изменения, произошедшие в стране со времени последнего доклада и сформулировал замечания и рекомендации Российской Федерации. Особое внимание будет уделено правовой позиции Комитета об осуществлении Россией эффективного контроля над территорией самопровозглашенных республик восточной Украины, а также заключению о необходимости эффрективной реализации в России Соображений Комитета. Основным методом исследования был избран анализ правовых позиций Комитета по правам человека, а также иностранной литературы, посвященной статусу правовых позиций Комитета. Научная новизна настоящей статьи заключается в том, что впервые произведен перевод и анализ заключений Комитета ОOH по правам человека по докладу Российской Федерации, принятому 31 марта 2015 года. В качестве выводов автор отмечает плюсы и минусы замечаний Комитета по правам человека.

Ключевые слова: ООН, комитет правам человека, доклад, международный пакт, свобода слова, независимость судебной власти, свобода ассочиачии, дискриминация, расизм, статус заключений.

Review: The article considers the remarks of the UN Human Rights Committee on the report of the Russian Federation about the fulfillment of the International Covenant on Civil and Political Rights. The Committee noted the positive changes which had taken place in the country since the previous report and formulated the remarks and recommendations to the Russian Federation. Special attention in the paper is paid to the legal position of the Committee about the efficiency of Russian control over the territory of the self-proclaimed republics of Eastern Ukraine and to the conclusion about the necessity of the efficient realization of the Committee's considerations in Russia. The study is based on the analysis of the legal provisions of the Human Rights Committee and the foreign literature devoted to the legal status of its provisions. The novelty of the research lies in the fact that this is the first translation and analysis of the remarks of the Committee on the report of the Russian Federation adopted on March 31, 2015. The author enumerates pluses and minuses of the remarks.
\end{abstract}

Keywords: discrimination, freedom of association, independence of judiciary, freedom of expression, international covenant, report, human rights committee, UNO, racism, status of conclusions.

$\mathrm{H}$ а сто тринадцатой сессии Комитета ООН по правам человека, закрытой 2 апреля 2015 года, был проанализирован доклад Российской Федерации об исполнении норм Международного пакта по гражданским и политическим правам. Учитывая сложность политической обстановки и насыщенность последних двух лет событиями, к которым было приковано внимание международной общественности, особенно интересно обратиться к тем вопросам, которые наиболее волновали Комитет и на те замечания, которые были сделаны в отношении России.[1]
Комитет отметил позитивные изменения, произошедшие в стране со времени последнего доклада. Этому было посвящено около 10 строчек из всего доклада, занимающего 12 страниц. В частности, были отмечены: расширение защиты прав инвалидов и ратификация Конвенции о правах инвалидов, введение норм о возможности компенсации вреда, причиненного чрезмерной длительностью судебного процесса, облегчение процедуры создания политических партий.

Обращаясь к замечаниям и рекомендациям, особое внимание уделим замечанию об отсутствии 
механизма исполнения мнений Комитета в России(1) и замечанию об обеспечении реализации положений Пакта на территории Восточной Украины (2).

1. Комитет ООН по правам человека, рассмотрев доклады о нарушении прав, предусмотренных Международным Пактом, на территории Восточной Украины предписал России «принять все организационные и законодательные меры для обеспечения полной реализации заключений Комитета» и «незамедлительно выполнять» рекомендации, связанные с нарушением права на эффективное средство правовой защиты. Подобное заключение было вызвано невозможностью пересмотра судебного решения в отношении Хорошенко А.А., обратившегося в Комитет с индивидуальной жалобой на нарушение Россией Международного пакта о гражданских и политических правах. Комитет принял Соображения, констатирующие нарушение Российской Федерацией прав А.А. Хорошенко, закрепленных статьей 6 Международного пакта о гражданских и политических правах в совокупности с его статьями 7, пунктами 1-4 статьи 9, пунктом 1 и подпунктами «a», «b», «d», «g» статьи 14. Комитет пришел к выводу о том, что Российская Федерация обязана обеспечить А.А. Хорошенко эффективное средство правовой защиты, включая повторное судебное разбирательство при соблюдении всех гарантий в соответствии с Пактом. Поскольку УПК РФ не предусматривает пересмотра решения в связи с новыми обстоятельствами на основании Соображений Комитета ООН по правам человека, при обращении в Генеральную прокуратуру и Верховный суд с заявлением о пересмотре решения, вступившего в законную силу, Хорошенко А.А. было отказано.

Насколько легитимно требование Комитета обеспечить выполнение его заключений? Ответ на этот вопрос можно найти, определив статус данных позиций Комитета и их место в правовой системе России. Согласно п. 4 ст. 40 Международного Пакта Комитет по правам человека препровождает Государствам-участникам свои доклады и такие замечания общего порядка, которые он сочтет целесообразными. Комитет по правам человека дополнительно разъясняет содержание и смысл этих прав. [2] Представители государств в ответ на замечания членов Комитета дают заверения, что их правительствами будет рассмотрен вопрос о возможности приведения своего законодательства и правоприменительной практики в большее соответствие с Пактом, отдельные государства вносят изменения в законодательные акты. [3] Комитет по правам человека указывает, что только $30 \%$ получаемых им ответов от государств отражают желание выполнять его решения или предлагают выплатить жертве компенсацию. [4] Но это делается лишь в рамках добровольно принятых на себя обязательств. Юрисдикция Комитета по правам человека, в отличие, например, от Европейского суда по правам человека, не была признана обязательной в случаях предполагаемого нарушения Пактов Российской Федерацией. Следовательно, само использование Комитетом слов, указывающих на должное поведение государства, уже является превышением полномочий. Следует отметить, что Комитет ООН по социальным, экономическим и культурным правам формулирует свои заключения по докладам государств в более мягкой форме, которая не идет в разрез с их рекомендательным характером. [5]

Принимая Замечание общего порядка № 33 об обязательствах государств-участников по Факультативному протоколу к Международному пакту о гражданских и политических правах, CCPR/C/ $\mathrm{GC} / 33,25$ июня 2009 г., Комитет указал, что его заключения «представляют собой авторитетное определение, выносимое учрежденным в соответствии с Международным пактом о гражданских и политических правах органом, на который возложена задача толкования этого документа», причем «характер этих соображений и придаваемое им значение вытекают из ключевой роли Комитета согласно Пакту и Факультативному протоколу». [6] Полагаем, что статус Заключительных Замечаний по результатам рассмотрения докладов стран может быть аналогично охарактеризован. Действительно, российские исследователи отмечают, что высказывания Комитета по конкретным правам и свободам «следует рассматривать лишь как квалифицированное мнение независимых экспертов, способствующих в конечном счете адекватному выполнению государствами своих обязательств по Пакту». [7] Некоторые западные ученые склонны к более критической оценке заключений Комитета по правам человека и отмечают их бессистемный и не всегда обоснованный характер, отмечая, что правовые позиции Комитета не заслуживают какой либо значимости в правовой системе. [8]

Подобное прочтение позиций Комитета, на наш взгляд, умаляет их значение. Не подвергая сомнению авторитетность заключений данного органа, отметим, что его заключения не является обязательным для исполнения государствами. 
Это лишь дополнительный материал для более правильного толкования Международного пакта. Данная особенность правового статуса замечаний Комитета $\mathrm{OOH}$ не раз отмечалась властями и судами государств, в отношении которых были приняты замечания. [9] Россия, в свою очередь, в ответе, представленном Комитету по правам человека по делу «Гридин против Российской Федерации» указала, что Комитет не является судом и его Соображения носят рекомендательный характер[10]. По существу, аналогичным образом был определен правовой статус заключений Комитета Конституционным Судом РФ. В определении от 28 июня 2012 года №1248-029, рассмотрев жалобу Хорошенко А.А., Суд указал, что Международный пакт о гражданских и политических правах и Факультативный протокол к нему не содержат «положений, непосредственно определяющих значение для государств-участников соображений Комитета по правам человека, принятых по индивидуальным сообщениям, однако это не освобождает Российскую Федерацию от добросовестного и ответственного выполнения соображений Комитета в рамках добровольно принятых на себя международно-правовых обязательств». Поскольку Международный Пакт не определяет значение заключительных замечаний Комитета по результатам рассмотрения докладов стран, то наиболее обоснованным будет вывод об их рекомендательном характере.

Таким образом, возвращаясь к первому замечанию Комитета об отсутствии в России механизма исполнения его заключений, мы можем сделать вывод о том, что Российская Федерация свободна в определении необходимости для создания подобного механизма, а данное замечание Комитета является свидетельством превышения полномочий и не отвечает требованию легитимности.

2. Комитет ООН по правам человека, рассмотрев доклады о нарушении прав, предусмотренных Международным Пактом, на территории Восточной Украины, призвал Россию обеспечить применение положений Пакта в отношении действий, совершенных вооруженными группами и властями самопровозглашенных народных республик Восточной Украины. Комитет был обеспокоен сообщениями о серьезных нарушений Пакта в Донбассе и посчитал, что Россия, по-видимому, имеет значительное влияние над территорией, которое может означать эффективный контроль. На этом основании, в котором нельзя не заметить неопределенности, Комитет призвал Россию обе- спечить применение положений Пакта в отношении действий, совершенных вооруженными группами и властями самопровозглашенных народных республик Восточной Украины. Следует отметить, что подход к экстра-территориальному применению Пакта в данном случае идет вразрез со сложившейся практикой Комитета по делам в отношении Израиля (территория Сектора Газа) или Бельгии (территория Сомали).[11] Кроме того, особенно интересно, что в отношении Крыма Комитет делает аналогичный вывод об эффективном контроле над его территорией со стороны Российской Федерации. Рассматривая данное замечание необходимо ответить на вопрос, что такое эффективный контроль над территорией другого государства?

В Замечании общего порядка № 31, адресованного Израилю в 2004 году, Комитет по правам человека указал на то, что государства должны обеспечить выполнение положений Пакта на всей свой территории, а также на той территории, над которой они осуществляют эффективный контроль вне зависимости от обстоятельств в результате которых такой контроль был установлен, таких как участие в международной миротворческой операции.

В 1998 году Комитет по правам человека, рассматривая доклад Израиля, отметил, что долговременное присутствие Израиля на оккупированных территориях, неоднозначное отношение Израиля к их будущему статусу, а также осуществления эффективной юрисдикции израильскими силами безопасности в регионе означает эффективный контроль над ним. В 2008 и 2010 году Генеральная ассамблея $\mathrm{OOH}$ заслушивала Доклады Специального докладчика по вопросу о положении в области прав человека на палестинских территориях, оккупированных с 1967 года. В данных документах был сделан вывод о том, что Израиль осуществляет эффективный контроль над Газой, поскольку контролирует ее внешние границы, воздушное пространство, территориальные воды, ведет реестр учета населения, налоговые поступления и правительственные функции. Кроме того, осуществляет регулярные военные вторжения и ракетные нападения. [12] Анализ данных документов позволяет сделать вывод о том, что признание $\mathrm{OOH}$ эффективного контроля одного государства над территорией другого до событий на Украине требовало серьезных оснований, и прежде всего, присутствия вооруженных сил на чужой территории, осуществление контроля над населением. В дан- 
ном контексте не безынтересно вспомнить заявления Банковича в ЕСПЧ о бомбардировках Белграда силами НАТО в 1999 г. [13]. Тогда Европейский Суд отказал в рассмотрении жалобы по существу, установив, что отсутствует какая-либо юрисдикционная связь между лицами, являющимися жертвами предполагаемых действий, и государствами-ответчиками. [14]

Обращаясь к тексту замечаний Комитета по правам человека довольно трудно определить, что же стало основанием вывода о том, что Россия осуществляет эффективный контроль над территорией самопровозглашенных республик восточной Украины. В отличие от замечания о несоблюдении прав человека на территории Крыма, где Комитет приводит список нарушений с указанием пострадавших лиц, замечание относительно восточной Украины обосновано лишь указанием на доклады о нарушениях прав человека. Интересно отметить, что Комитет ссылается на приведенное выше Замечание общего порядка, адресованное Израилю. Можно ли сравнить оккупацию Израилем Сектора Газа и ситуацию на восточной Украине? Ответ может быть только отрицательным: события на территории самопровозглашенных республик сви- детельствуют о том, что Российская Федерация не осуществляет над ними эффективный контроль по смыслу, придаваемому данному понятию $00 \mathrm{H}$. Следовательно, вывод Комитета ошибочен, а его расхождение с предыдущей практикой Органов ООН свидетельствует о некоторой предвзятости по отношению к России.

В заключение отметим, что наряду с указанными замечаниями Комитет предписал России бороться с ксенофобией, расовой дискриминацией. Особое внимание было уделено защите прав лиц с нетрадиционной ориентацией. Кроме того, была отмечена необходимость эффективной защиты права на свободу собраний и свободу слова, прекращение преследований в отношении правозащитников и журналистов. Таким образом, оценка Комитетом по правам человека доклада России наряду с малообоснованными и нелегитимными замечаниями, рассмотренными в настоящей статье, содержит ценные рекомендации, которые могут внести свой вклад в создание в России эффективного механизма защиты прав человека. При этом чрезвычайно важно, чтобы эти правовые позиции учитывали и уважали конституционные ценности России и ее суверенитет.

\section{Библиография:}

1. Human rights Committee, Concluding observations on the seventh periodic report of the Russian Federation, доступен по адресу: http://tbinternet.ohchr.org/_layouts/treatybodyexternal/SessionDetails1.aspx?SessionID=897\&Lang=en

2. Новак М. Международный пакт о гражданских и политических правах // Хански Р., Сукси М. (ред.) Введение в вопросы международной защиты прав человека. Учебное пособие. Турку. 1999. С. 87.

3. Манов Б.Г. ООН и содействие осуществлению соглашений о правах человека. М., 1986. С. 94.

4. А.М. Солнцев, А.Е. Конева, Юридический статус актов договорных органов по правам человека в национальных правовых системах. «международное правосудие», 2013, n 4.

5. См., например, Заключительные замечания, принятые на последней 53 сессии Комитета. http://tbinternet.ohchr. org/_layouts/treatybodyexternal/SessionDetails1.aspx?SessionID=965\&Lang=en (доступ 05.04.2015).

6. Доступно по адресу: https://www1.umn.edu/humanrts/russian/gencomm/Rhrcom33.html (доступ 04.04.20015).

7. Панова Е.В. Международно-правовые основы деятельности комитета по правам человека: автореферат диссертации на соискание ученой степени кандидата юридических наук. Москва. 2005. С. 22.

8. P. Alston, 'The Historical Origins of the Concept of «General Comments» in Human Rights Law' in L. Boisson de Chazournes and V. Gowland Debbas (eds.), The International Legal System in Quest of Equity and Universality: Liber Amicorum Georges Abi-Saab (The Hague: Martinus Nijhoff, 2001),p. 764.

9. См. примеры, С.С. Дикман, Юридическая природа решений комитета ООН по правам человека: основные проблемы. Труды Института государства и права Российской академии наук № 1/2010 Москва, 2010 г. С. $75-87$.

10. Солнцев А.М., Конева А.Е. Юридический статус актов договорных органов по правам человека в национальных правовых системах // Международное правосудие.-М: Институт права и публичной политики, 2013 , №4. С. 87.

11. См. Dominic McGoldric, Extraterritorial application Of The International Covenant On Civil And Political Rights in Extraterritorial Application of Human Rights Treaties, edited by Fons Coomans, Menno T. Kamminga. Intersentia, 2004. P. 41-72.

12. Доклад Специального докладчика по вопросу о положении в области прав человека на палестинских территориях, оккупированных с 1967 года. На русском языке доступен по адресу: http://www.refworld.org/cgi-bin/texis/ vtx/rwmain/opendocpdf.pdf?reldoc=y\&docid=47317e132 (доступ 04.04.2015).

13. ЕСПЧ, Банкович и другие против Бельгии, Чехии, Дании, Франции, Германии, Греции, Венгрии, Исландии, Италии, Люксембурга, Нидерландов, Норвегии, Польши, Португалии, Испании, Турции И Великобритании (52207/99) РЕШЕНИЕ ПО ВОПРОСУ ПРИЕМЛЕМОСТИ 12 декабря 2001 г

14. Надо отметить, что в 2011 году ЕСПЧ пересмотрел свои позиции по поводу экстра-территориального применения ЕКПЧ и установил критерии, которым должен отвечать контроль государства над территорией другого 
государства. См. Шанта Бхавнани, ЕСПЧ расширяет сферу применения Конвенции за пределы Совета Европы. Бюллетень EUROPEAN HUMAN RIGHTS ADVOCACY CENTRE. ЗИМA 2011 ВЫПУСК 2(9), с. 1.

15. С. Н. Белясов Международное сотрудничество Российской Федерации в сфере защите прав и свобод человека и гражданина // Право и политика.-2011.-11.-С. 1916-1923.

16. Техники эффективной коммуникации в политике: уч.-метод. пособие / А.В. Манойло, А.И. Петренко, О.М. ХауерТюкаркина. - М.: Издательство «Известия», 2015. - 32 с

17. Codagnone C., Filippov V. Equity, exit end national identity in a multinational federation: the "multi-cultural constitutional patriotism" project in Russia. // Journal of ethnic and migration studies. 2000. V. 26. № 2.. Р. 263-288.

18. Будаев А.В. Сравнительный анализ «мягкой силы» во внешней политике России и Бразилии. // Латинская Америка. 2014. № 4. С. 24-31.

\section{References (transliterated):}

1. Human rights Committee, Concluding observations on the seventh periodic report of the Russian Federation, dostupen po adresu: http://tbinternet.ohchr.org/_layouts/treatybodyexternal/SessionDetails1.aspx?SessionID=897\&Lang=en

2. Novak M. Mezhdunarodnyi pakt o grazhdanskikh i politicheskikh pravakh // Khanski R., Suksi M. (red.) Vvedenie v voprosy mezhdunarodnoi zashchity prav cheloveka. Uchebnoe posobie. Turku. 1999. S. 87.

3. Manov B.G. OON i sodeistvie osushchestvleniyu soglashenii o pravakh cheloveka. M., 1986. S. 94.

4. A.M. Solntsev, A.E. Koneva, Yuridicheskii status aktov dogovornykh organov po pravam cheloveka v natsional'nykh pravovykh sistemakh. «mezhdunarodnoe pravosudie», 2013, n 4.

5. Sm., naprimer, Zaklyuchitel'nye zamechaniya, prinyatye na poslednei 53 sessii Komiteta. http://tbinternet.ohchr.org/_ layouts/treatybodyexternal/SessionDetails1.aspx?SessionID=965\&Lang=en (dostup 05.04.2015).

6. Dostupno po adresu: https://www1.umn.edu/humanrts/russian/gencomm/Rhrcom33.html (dostup 04.04.20015).

7. Panova E.V. Mezhdunarodno-pravovye osnovy deyatel'nosti komiteta po pravam cheloveka: avtoreferat dissertatsii na soiskanie uchenoi stepeni kandidata yuridicheskikh nauk. Moskva. 2005. S. 22.

8. P. Alston, 'The Historical Origins of the Concept of «General Comments» in Human Rights Law' in L. Boisson de Chazournes and V. Gowland Debbas (eds.), The International Legal System in Quest of Equity and Universality: Liber Amicorum Georges Abi-Saab (The Hague: Martinus Nijhoff, 2001),p. 764.

9. Sm. primery, S.S. Dikman, Yuridicheskaya priroda reshenii komiteta OON po pravam cheloveka: osnovnye problemy. Trudy Instituta gosudarstva i prava Rossiiskoi akademii nauk № 1/2010 Moskva, 2010 g. S. 75-87.

10. Solntsev A.M., Koneva A.E. Yuridicheskii status aktov dogovornykh organov po pravam cheloveka v natsional'nykh pravovykh sistemakh // Mezhdunarodnoe pravosudie.-M: Institut prava i publichnoi politiki, 2013, №4. S. 87.

11. Sm. Dominic McGoldric, Extraterritorial application of The International Covenant On Civil And Political Rights in Extraterritorial Application of Human Rights Treaties, edited by Fons Coomans, Menno T. Kamminga. Intersentia, 2004. P. 41-72.

12. Doklad Spetsial'nogo dokladchika po voprosu o polozhenii v oblasti prav cheloveka na palestinskikh territoriyakh, okkupirovannykh s 1967 goda. Na russkom yazyke dostupen po adresu: http://www.refworld.org/cgi-bin/texis/vtx/ rwmain/opendocpdf.pdf?reldoc=y\&docid=47317e132 (dostup 04.04.2015).

13. ESPCh, Bankovich i drugie protiv Bel'gii, Chekhii, Danii, Frantsii, Germanii, Gretsii, Vengrii, Islandii, Italii, Lyuksemburga, Niderlandov, Norvegii, Pol'shi, Portugalii, Ispanii, Turtsii I Velikobritanii $(52207 / 99)$ REShENIE PO VOPROSU PRIEMLEMOSTI 12 dekabrya $2001 \mathrm{~g}$

14. Nado otmetit', chto v 2011 godu ESPCh peresmotrel svoi pozitsii po povodu ekstra-territorial'nogo primeneniya EKPCh i ustanovil kriterii, kotorym dolzhen otvechat' kontrol' gosudarstva nad territoriei drugogo gosudarstva. Sm. Shanta Bkhavnani, ESPCh rasshiryaet sferu primeneniya Konventsii za predely Soveta Evropy. Byulleten' EUROPEAN HUMAN RIGHTS ADVOCACY CENTRE. ZIMA 2011 VYPUSK 2(9), s. 1.

15. S. N. Belyasov Mezhdunarodnoe sotrudnichestvo Rossiiskoi Federatsii v sfere zashchite prav i svobod cheloveka i grazhdanina // Pravo i politika.-2011.-11.-S. 1916-1923.

16. Tehniki effektivnoy kommunikacii v politike: uch.-metod. posobie / A.B. Manoylo, A.I. Petrenko, O.M. Hauer-Tyukarkina. M.: Izdatelstvo «Izvestiya», 2015. - 32 s.

17. Codagnone C., Filippov V. Equity, exit end national identity in a multinational federation: the "multi-cultural constitutional patriotism" project in Russia. // Journal of ethnic and migration studies. 2000. V. 26. № 2. P. 263-288.

18. Budaev A.B. Sravnitelniy analiz «myagkoy sili» vo vneshney politike Rossii i Brazilii. // Latinskaya Amerika. 2014 . № 4. S. 24-31. 